\title{
Synthesis of Copper Nanoparticles by Thermal Decomposition and Their Antimicrobial Properties
}

\author{
R. Betancourt-Galindo, P. Y. Reyes-Rodriguez, B. A. Puente-Urbina, C. A. Avila-Orta, \\ O. S. Rodríguez-Fernández, G. Cadenas-Pliego, R. H. Lira-Saldivar, and L. A. García-Cerda \\ Departamento de Materiales Avanzados, Centro de Investigación en Química Aplicada, Boulevard Enrique Reyna Hermosillo No. 140, \\ 25294 Saltillo, COAH, Mexico \\ Correspondence should be addressed to R. Betancourt-Galindo; rebeca.betancourt@ciqa.edu.mx and \\ L. A. García-Cerda; luis.garcia@ciqa.edu.mx
}

Received 4 October 2013; Revised 23 November 2013; Accepted 23 November 2013; Published 15 January 2014

Academic Editor: William W. Yu

Copyright (C) 2014 R. Betancourt-Galindo et al. This is an open access article distributed under the Creative Commons Attribution License, which permits unrestricted use, distribution, and reproduction in any medium, provided the original work is properly cited.

Copper nanoparticles were synthesized by thermal decomposition using copper chloride, sodium oleate, and phenyl ether as solvent agents. The formation of nanoparticles was evidenced by the X-ray diffraction and transmission electron microscopy. The peaks in the XRD pattern correspond to the standard values of the face centered cubic (fcc) structure of metallic copper and no peaks of other impurity crystalline phases were detected. TEM analysis showed spherical nanoparticles with sizes in the range of 4 to $18 \mathrm{~nm}$. The antibacterial properties of copper nanoparticles were evaluated in vitro against strains of Staphylococcus aureus and Pseudomonas aeruginosa. The antibacterial activity of copper nanoparticles synthesized by thermal decomposition showed significant inhibitory effect against these highly multidrug-resistant bacterial strains.

\section{Introduction}

Recently metallic nanoparticles (NPs) have attracted great interest because of their unique physical and chemical properties. Their properties can be controlled depending on the synthesis method. One of the main effects, which are enhanced by controlling particle size, is their antimicrobial action $[1,2]$. The antimicrobial activity of NPs is known to be a function of surface area in contact with microorganisms. For this reason, high surface area NPs assure a wide range of reactions on the surface of microorganisms, inhibiting the normal function of cells or causing cell death [3].

Several methods have been used for the formation of copper nanoparticles. One of the first reported methods to obtain inorganic NPs is the chemical coprecipitation method, which involves nucleation and growth during the same process [4], but the main disadvantage of this process is the formation of agglomerated NPs with a wide size distribution. Nanometric particles with size control have been obtained through homogeneous precipitation reactions, which involve separation of nucleation and growth process. Under conditions of homogeneous precipitation, an abrupt nucleation occurs when reactive concentrations reach a supercritical saturation point [5], generating this way a homogeneous growth by solutes diffusion from solution to surface, achieving their final size. The key to obtain homogeneous particle size is the separation of nucleation and growth steps, avoiding nucleation during NPs growth step; if performed with direct heating of the mixture, a wide size distribution of NPs can be produced $[5,6]$.

Thermal decomposition of metallic precursors in presence of organic surfactants at high temperature is a method widely used due to its ease to produce highly crystalline NPs with size distribution control [5, 7-11]. In the particular case of $\mathrm{Cu}$ NPs, low redox potential causes surface oxidation which decreases their antimicrobial characteristics, this is due to the fact that metallic copper $\left(\mathrm{Cu}^{0}\right)$ is more reactive than copper oxide [12]. Therefore, in order to obtain Cu NPs with high antimicrobial properties, the size control of NPs and the presence of a surface coating to prevent their oxidation are 
very important. Lately a straightforward approach to oxidefree $\mathrm{Cu}$ NPs by thermal decomposition of a copper precursor has been reported for industrial applications [13].

Although only a few studies have described the antibacterial properties of copper nanoparticles, they show that copper nanoparticles have a significant potential as bactericidal agents. Hence, in this work we report the synthesis of copper NPs by thermal decomposition using phenyl ether and oleic acid, which act like an organic agent to control the growth of NPs. The obtained $\mathrm{Cu}$ NPs were tested in vitro against the bacterial strains $S$. aureus and $P$. aeruginosa, which are some of the main pathogens causing nosocomial infections worldwide [14].

\section{Experimental}

Copper chloride, oleic acid, and phenyl ether were provided by Sigma Aldrich; sodium oleate was provided by TCI; hexane and ethanol were provided by J. T. Baker. All reactants were used as received by the supplier. In order to evaluate the antimicrobial properties against human gram negative pathogenic bacteria, we used an inoculum containing $10^{5} \mathrm{CFU} \mathrm{mL}^{-1}$ (colony forming units per milliliter) of $S$. aureus (ATCC 6538) and $P$. aeruginosa (ATCC 13388), in Mueller Hinton broth provided by BD Bioxon.

2.1. Synthesis of Copper Nanoparticles. In a typical synthesis, $1.08 \mathrm{~g}$ of copper chloride and $3.65 \mathrm{~g}$ of sodium oleate were dissolved in a mixture of hexane, ethanol, and distilled water. The solution was heated and refluxed during $4 \mathrm{~h}$, and later it was transferred to a separation funnel to eliminate the aqueous residues. The organic phase with copper-oleate complex and hexane was washed three times with distilled water. Afterwards the copper-oleate complex was transferred to a Petri dish to help evaporate the residual solvent. Next $3.6 \mathrm{~g}$ of copper-oleate complex was mixed with $1.14 \mathrm{~g}$ of oleic acid and $20 \mathrm{~g}$ of phenyl ether at room temperature. The solution was heated at $250^{\circ} \mathrm{C}$ for $30 \mathrm{~min}$. During the course of the reaction, the solution turned brown in color indicating the formation of $\mathrm{Cu}$ NPs. The resulting mix was cooled at room temperature and the precipitate was washed a few times with ethanol to eliminate solvent and residues; finally the NPs were collected by centrifugation.

2.2. Characterization of Copper Nanoparticles. XRD patterns were obtained using a diffractometer Siemens D-500 $(\mathrm{CuK} \alpha$, $25 \mathrm{~mA}, 35 \mathrm{kV}$ ). Nanoparticles size was measured by means of a transmission electron microscope JEOL Titan. FTIR spectra of copper NPs were recorded in KBr pellets on Nicolet Magna-IR Spectrometer model 550.

2.3. Antimicrobial Assays. The antimicrobial activity of $\mathrm{Cu}$ NPs was tested against $P$. aeruginosa (ATCC 13388) and S. aureus (ATCC 6538). The assays were set by preparing serial dilutions containing $\mathrm{Cu}$ NPs at concentrations of 200 , $400,800,1600$, and $3200 \mu \mathrm{g} \mathrm{mL}^{-1}$, which were suspended in Mueller Hinton broth by sonication. Each dilution of NPs was added to $10^{5} \mathrm{CFU} \mathrm{mL}^{-1}$ of bacterial suspension and incubated at $37^{\circ} \mathrm{C}$ during $16 \mathrm{~h}$ and $200 \mathrm{rpm}$. After that time, bacterial growth was determined by optical density measurements at $600 \mathrm{~nm}$ to obtain the minimal inhibitory concentration (MIC) and minimal bactericidal concentration (MBC). Inhibition rates were calculated by using the following equation:

$$
\text { inhibition }(\%)=\frac{A_{0}-A}{A_{0}} * 100 \text {, }
$$

where $A_{0}$ is the absorbance of the control and $A$ is that of the test sample.

The $\mathrm{Cu}$ NPs antibacterial effect was determined using a medium nutrient agar adding 800,1600 , and $3200 \mu \mathrm{g} \mathrm{mL}^{-1}$ of NPs. Next a $100 \mu \mathrm{L}$ solution containing $P$. aeruginosa and/or $S$. aureus incubated at $37^{\circ} \mathrm{C}$ during $16 \mathrm{~h}$ was added to the growth medium containing the three concentrations. The medium was streaked with a sterile loop across the surface of the agar. The dishes were incubated at $37^{\circ} \mathrm{C}$ during $16 \mathrm{~h}$ to allow bacteria to reproduce.

\section{Results and Discussion}

Figure 1 shows XRD patterns of copper nanoparticles obtained by thermal decomposition of copper-oleate complex. In comparison to a copper standard (JCPDS 04-0836), the characteristic diffraction peaks of copper located at $43.7^{\circ}$, $50.7^{\circ}$, and $74.3^{\circ}$ were observed. They correspond to the (111), (200), and (220) planes of the fcc structure, respectively. No other impurity peak was detected in the sample. This result confirms that with this process it is possible to obtain pure copper NPs.

The FTIR spectrum of copper nanoparticles obtained by thermal decomposition process is presented in Figure 2. This analysis was used to determine the functional organic groups in the surface of the nanoparticles generated by oleic acid. Two bands at 2901 and $2838 \mathrm{~cm}^{-1}$ can be seen, and they are attributed to symmetric and asymmetric stretching of $\mathrm{CH}_{2}$ group and terminal groups $-\mathrm{CH}_{3}$ and $=\mathrm{CH}$ which correspond to oleic acid. Other absorption bands of carboxylate coordination and metals located at 1623 and $1450 \mathrm{~cm}^{-1}$ for asymmetric stretching $\mathrm{COO}^{-}$and bands located at 1123 and $847 \mathrm{~cm}^{-1}$ corresponding to symmetric stretching of $\mathrm{COO}^{-}$ group can be seen as well [15]. Similar results using this method were reported by Roca et al. [7].

TEM micrograph of copper nanoparticles and their size distribution is shown in Figure 3(a), which displays spherical NPs with sizes below $20 \mathrm{~nm}$. The distribution uniformity of NPs due to oleic acid chemically bound at their surface is also shown. The particle size distribution (Figure 3(b)) was obtained by measuring the diameter of the particles from different parts of the grid for an average number of particles close to 300. The particle size ranges between 4 and $19 \mathrm{~nm}$ with an average size of $9 \mathrm{~nm}$.

Comparing these results with those generated by other scientists [15], the particle size obtained by this process is smaller $( \pm 9 \mathrm{~nm})$. The presence of an organic compound such as oleic acid allows particle size to be controlled and at the same time avoids its agglomeration and oxidation. This 


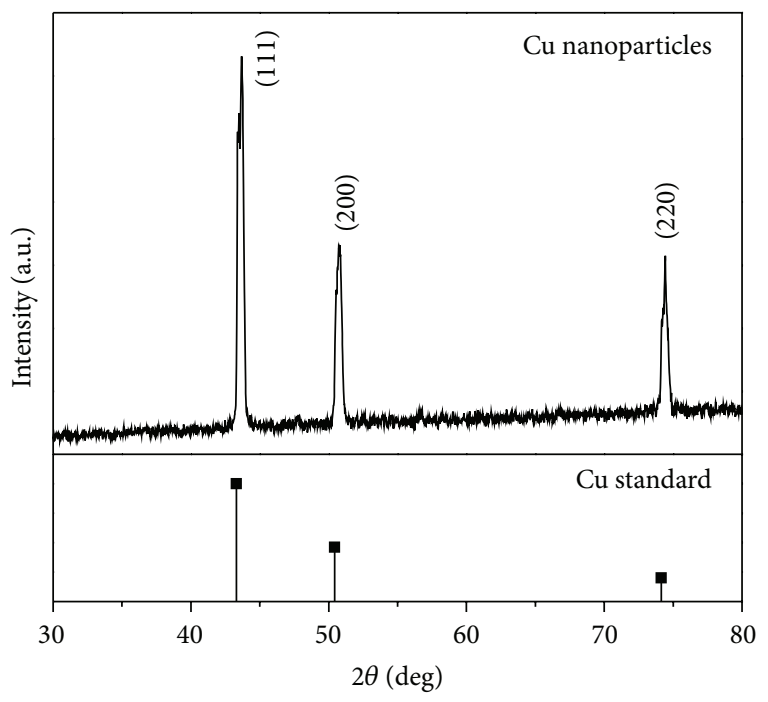

FIGURE 1: XRD patterns of $\mathrm{Cu}$ nanoparticles obtained by thermal decomposition and $\mathrm{Cu}$ standard (JCPDS 04-0836).

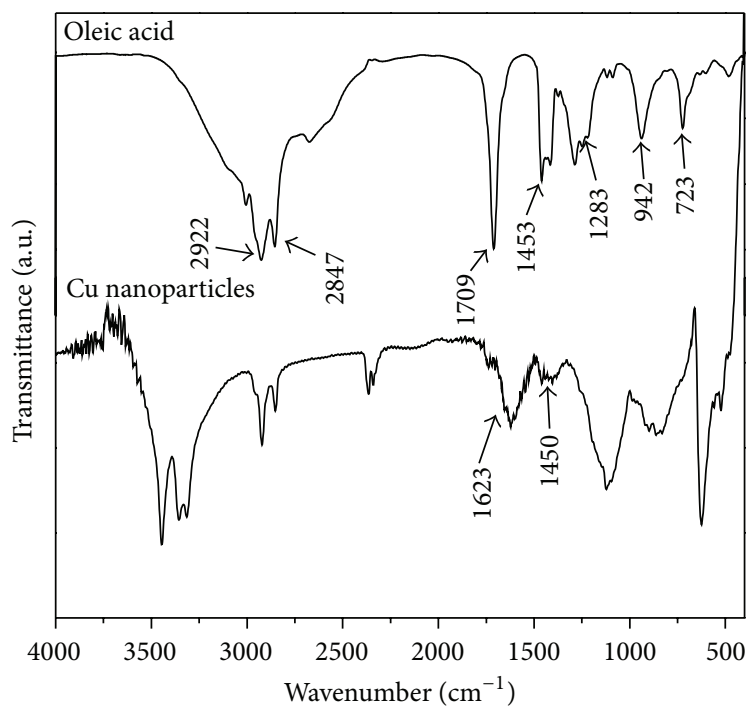

FIGURE 2: FTIR spectrum of copper nanoparticles.

synthesis method depends on the high reactivity of copper complex as well as on its concentration and agitation speed during the reaction. Both factors are very specific for controlling the morphology, particle size, and their distribution.

The antimicrobial activity of $\mathrm{Cu}$ NPs against the bacterial strains S. aureus and P. aeruginosa is shown in Table 1. It is evident that for both bacteria there was an increase in the inhibitory activity (\%) as the Cu NPs concentration increased. With $800 \mu \mathrm{g} \mathrm{mL}^{-1}$ a noticeable antibacterial effect was attained on $P$. aeruginosa (99.9\%), however at the same dose no inhibition at all (0\%) was detected on S. aureus. A higher concentration $\left(1600 \mu \mathrm{g} \mathrm{mL}^{-1}\right)$ reported similar inhibitory effect ( $99 \%$ and $100 \%$ ) against $P$. aeruginosa and $S$. aureus, respectively. The highest dosage evaluated $\left(3200 \mu \mathrm{g} \mathrm{mL}^{-1}\right)$ also caused a total inhibition $(100 \%)$ on
TABLE 1: Copper nanoparticles concentrations tested for their in vitro inhibitory (\%) effect on bacterial strains of $S$. aureus and $P$. aeruginosa.

\begin{tabular}{lcc}
\hline \multirow{2}{*}{ Concentration $\left(\mu \mathrm{g} \mathrm{mL}^{-1}\right)$} & \multicolumn{2}{c}{ Inhibition (\%) } \\
& S. aureus & P. aeruginosa \\
\hline 3200 & 99.6 & 100 \\
1600 & 99 & 100 \\
800 & 0 & 99.9 \\
400 & 0 & 10.3 \\
200 & 0 & 0 \\
\hline
\end{tabular}

P. aeruginosa, demonstrating its bactericidal effect. However, with the same dose S. aureus reported $99.6 \%$ inhibition. This outcome suggests that the quantity of NPs in the solution was not enough to display a full antibacterial activity against this bacterial strain. This outcome is similar to that of Cioffi et al. [16] where they documented the bacteriostatic properties of copper NPs on S. aureus. In a similar study Ruparelia et al. [1] tested the antimicrobial properties of silver and copper NPs against $E$. coli (four strains), B. subtilis, and S. aureus (three strains). Their studies with E. coli and $S$. aureus revealed greater effectiveness of the silver Nps compared to copper NPs; however, B. subtilis showed the highest sensitivity to NPs compared to the other strains and was more negatively affected by the copper NPs.

The in vitro determination of $\mathrm{MBC}$ of $\mathrm{Cu}$ NPs at each of the five tested concentrations is shown in Figures 4 and 5. Our results point out that $S$. aureus and $P$. aeruginosa were inhibited at 99.6 and $100 \%$, respectively, with the $3200 \mu \mathrm{g} \mathrm{mL}^{-1}$ dose. Concentrations at 200 and $400 \mu \mathrm{g} \mathrm{mL}^{-1}$ did not inhibit the growth of $S$. aureus and displayed only a minor antibacterial effect (10.3\%) on P. aeruginosa. For this reason, the bacterial sensitivity to $\mathrm{Cu}$ NPs was found to vary depending on the microbial species. Similar results regarding the antimicrobial effect of $\mathrm{Cu}$ NPs against bacterial and fungal strains have been demonstrated by Ramyadevi et al. [17]. They reported the antimicrobial activity of $\mathrm{Cu}$ NPs against Micrococcus luteus, S. aureus, E. coli, Klebsiella pneumoniae, and $P$. aeruginosa and on several funguses like Aspergillus flavus, A. niger, and C. albicans. The Cu NPs showed more inhibitory activity in bacteria than on funguses.

The observed antimicrobial effect of Cu NPs is not merely due to their release of metal ions but can also be attributed to their morphology, mainly their small size and high surface area to volume ratio, which allows them to interact closely with microbial membranes of each bacterium [18]. In a similar way the antibacterial activity of silver NPs has been reported on the same bacterial strains [19]. The in vitro antibacterial effect of $\mathrm{Cu}$ NPs observed in this work is shown in a series of pictures; Figure 4 clearly shows that $P$. aeruginosa was more sensitive to the effect of Cu NPs compared to $S$. aureus, since with $1600 \mu \mathrm{g} \mathrm{mL} \mathrm{m}^{-1}$ dose the antibacterial effect was evident on Petri dishes.

On the other hand, Figure 5 clearly shows that a concentration of $3200 \mu \mathrm{g} \mathrm{mL}^{-1}$ was required to completely inhibit the bacterial growth of $S$. aureus. This outcome points out 


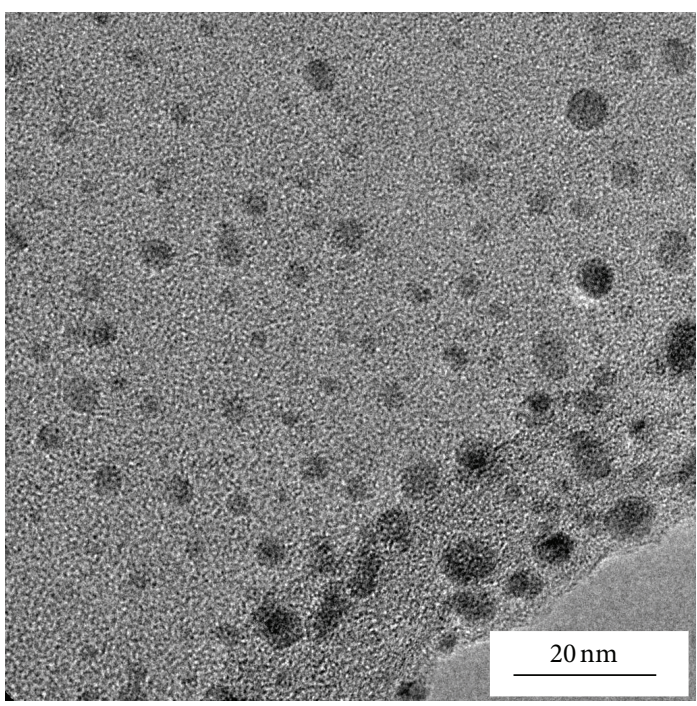

(a)

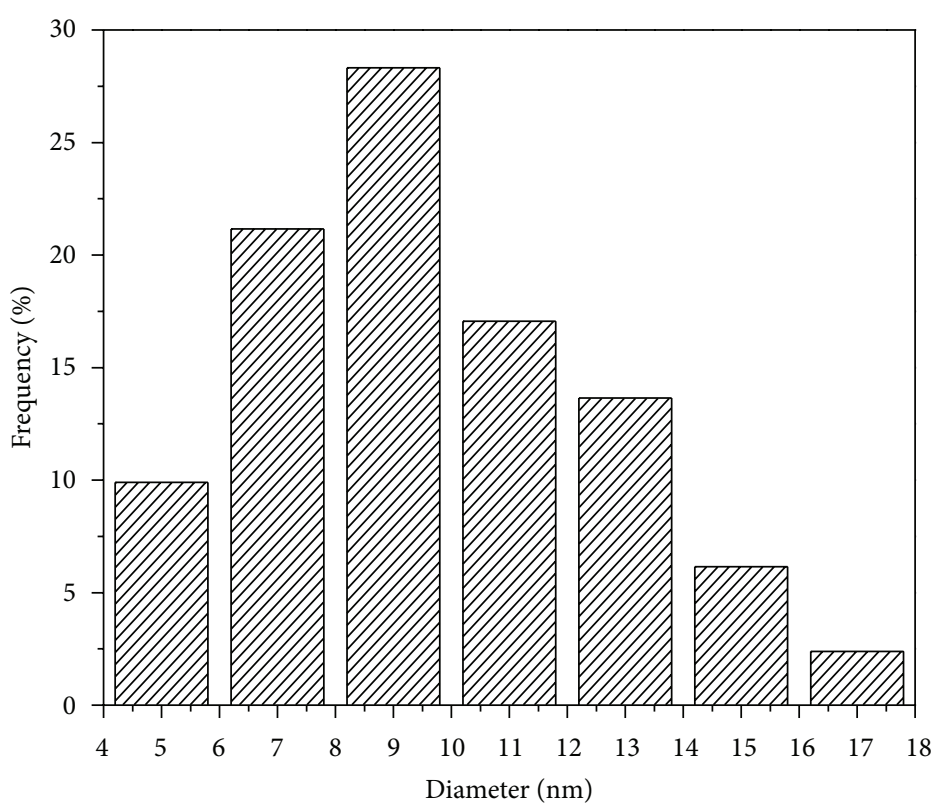

(b)

FIGURE 3: TEM micrograph of copper nanoparticles obtained by thermal decomposition (a) and size distribution histogram (b).
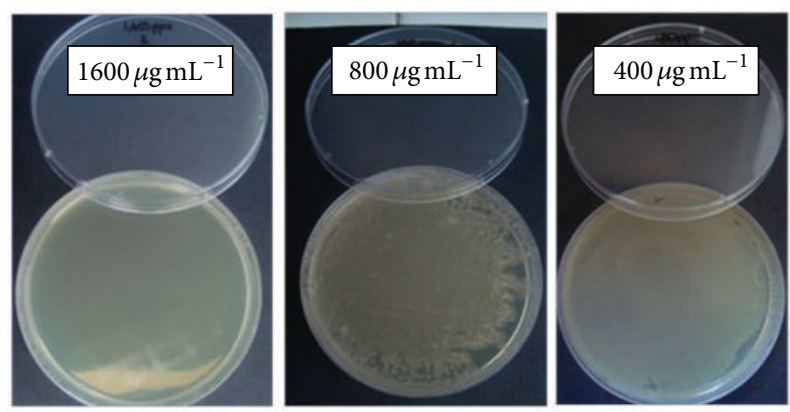

FIgURE 4: Antibacterial in vitro effect of copper nanoparticles at three concentrations on P. aeruginosa.
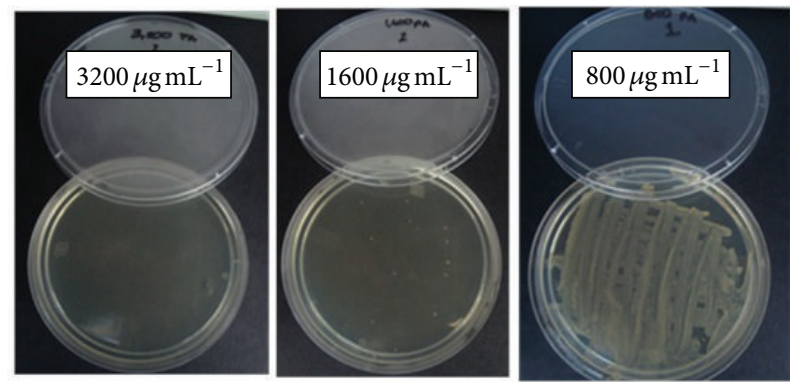

FIGURE 5: Antibacterial in vitro effect of copper nanoparticles at three concentrations on Staphylococcus aureus.

that this strain is more tolerant to the in vitro antibacterial effect of $\mathrm{Cu}$ NPs in comparison to P. aeruginosa, given that only $50 \%$ of copper nanoparticles concentration was required in order to inhibit any propagation of CFU. The antibacterial effect of copper oxide nanoparticles against $S$. aureus and $E$. coli has been also demonstrated by Ren et al. [20] with similar concentrations ranging from $100 \mu \mathrm{g} \mathrm{mL}^{-1}$ to $5000 \mu \mathrm{g} \mathrm{mL}^{-1}$.

According to the literature, the better inhibitory effect observed in P. aeruginosa than in S. aureus is related to the difference in the outer casing of these bacteria $[19,21]$. A Gram positive bacterium, as $S$. aureus, has a thick layer of peptidoglycan (a sugar-protein shell) that the $\mathrm{Cu}$ ions can penetrate. A Gram negative bacterium, as P. aeruginosa, has an outer membrane covering the thin layer of peptidoglycan on the outside. This outer membrane prevents the $\mathrm{Cu}$ ions from penetrating. The copper ions released by the nanoparticles may attach to the negatively charged bacterial cell wall and rupture it, thereby leading to protein denaturation and cell death [3].

\section{Conclusions}

Copper spherical nanoparticles in the range of 4 to $18 \mathrm{~nm}$ synthesized by thermal decomposition were evidenced by the X-ray diffraction and transmission electron microscopy. Copper nanoparticles showed an inhibitory effect against $S$. aureus $(99.6 \%)$ and P. aeruginosa (100\%) with $3200 \mu \mathrm{g} \mathrm{mL}^{-1}$, respectively. Therefore according to the results, we can conclude that copper metallic nanoparticles have a commercial potential to be used in public health issues, for prevention of food spoilage and for agricultural purposes.

\section{Conflict of Interests}

The authors declare that there is no conflict of interests regarding the publication of this paper. 


\section{Acknowledgments}

This work was supported by CONACYT under Grant no. CB2009/133991. P. Y. Reyes-Rodriguez thanks CONACYT for the Scholarship 335331. The Mexican partners in the CuVito project kindly acknowledge that the research leading to these results has received funding support from CONACYT under Grant no. 127151. The authors would like to thank H. Ortega and E. Diaz-Barriga for performing antimicrobial assays and TEM images.

\section{References}

[1] J. P. Ruparelia, A. K. Chatterjee, S. P. Duttagupta, and S. Mukherji, "Strain specificity in antimicrobial activity of silver and copper nanoparticles," Acta Biomaterialia, vol. 4, no. 3, pp. 707-716, 2008.

[2] G. Ren, D. Hu, E. W. C. Cheng, M. A. Vargas-Reus, P. Reip, and R. P. Allaker, "Characterisation of copper oxide nanoparticles for antimicrobial applications," The International Journal of Antimicrobial Agents, vol. 33, no. 6, pp. 587-590, 2009.

[3] K. Y. Yoon, J. H. Byeon, J. H. Park, and J. Hwang, "Susceptibility constants of Escherichia coli and Bacillus subtilis to silver and copper nanoparticles," Science of the Total Environment, vol. 373, no. 2-3, pp. 572-575, 2007.

[4] B. L. Cushing, V. L. Kolesnichenko, and C. J. O'Connor, "Recent advances in the liquid-phase syntheses of inorganic nanoparticles," Chemical Reviews, vol. 104, no. 9, pp. 3893-3946, 2004.

[5] P. Tartaj, M. del Puerto Morales, S. Veintemillas-Verdaguer, T. González-Carreño, and C. J. Serna, "The preparation of magnetic nanoparticles for applications in biomedicine," Journal of Physics D, vol. 36, no. 13, pp. R182-R197, 2003.

[6] J. Xie, S. Peng, N. Brower, N. Pourmand, S. X. Wang, and S. Sun, "One-pot synthesis of monodisperse iron oxide nanoparticles for potential biomedical applications," Pure and Applied Chemistry, vol. 78, no. 5, pp. 1003-1014, 2006.

[7] A. G. Roca, M. P. Morales, and C. J. Serna, "Synthesis of monodispersed magnetite particle from different precursors," IEEE Transactions on Magnetics, vol. 42, no. 10, pp. 3025-3040.

[8] S. Sun, H. Zeng, D. B. Robinson et al., "Monodisperse $\mathrm{MFe}_{2} \mathrm{O}_{4}$ $(\mathrm{M}=\mathrm{Fe}, \mathrm{Co}, \mathrm{Mn})$ nanoparticles," Journal of the American Chemical Society, vol. 126, no. 1, pp. 273-279, 2004.

[9] P. Guardia, B. Batlle-Brugal, A. G. Roca et al., "Surfactant effects in magnetite nanoparticles of controlled size," Journal of Magnetism and Magnetic Materials, vol. 316, no. 2, pp. e756e759, 2007.

[10] A. G. Roca, M. P. Morales, K. O’Grady, and C. J. Serna, "Structural and magnetic properties of uniform magnetite nanoparticles prepared by high temperature decomposition of organic precursors," Nanotechnology, vol. 17, no. 11, pp. 27832788, 2006.

[11] S. Sun and H. Zeng, "Size-controlled synthesis of magnetite nanoparticles," Journal of the American Chemical Society, vol. 124 , no. 28, pp. 8204-8205, 2002.

[12] M. Raffi, S. Mehrwan, T. M. Bhatti et al., "Investigations into the antibacterial behavior of copper nanoparticles against Escherichia coli," Annals of Microbiology, vol. 60, no. 1, pp. 75-80, 2010.

[13] D. Adner, M. Korb, S. Schulze, M. Hietschold, and H. Lang, "A straightforward approach to oxide-free copper nanoparticles by thermal decomposition of a copper(I) precursor," Chemical Communications, vol. 49, pp. 6855-6857, 2013.

[14] H. Wisplinghoff, H. Seifert, S. Tallent, T. Bischoff, R. Wenzel, and M. B. Edmond, "Nosocomial bloodstream infections in pediatric patients in United States hospitals: epidemiology, clinical features and susceptibilities," Pediatric Infectious Disease Journal, vol. 22, no. 8, pp. 686-691, 2003.

[15] M. Salavati-Niasari, F. Davar, and N. Mir, "Synthesis and characterization of metallic copper nanoparticles via thermal decomposition," Polyhedron, vol. 27, no. 17, pp. 3514-3518, 2008.

[16] N. Cioffi, L. Torsi, N. Ditaranto et al., "Copper nanoparticle/polymer composites with antifungal and bacteriostatic properties," Chemistry of Materials, vol. 17, no. 21, pp. 5255-5262, 2005.

[17] J. Ramyadevi, K. Jeyasubramanian, A. Marikani, G. Rajakumar, and A. A. Rahuman, "Synthesis and antimicrobial activity of copper nanoparticles," Materials Letters, vol. 71, pp. 114-116, 2012.

[18] J. R. Morones, J. L. Elechiguerra, A. Camacho et al., "The bactericidal effect of silver nanoparticles," Nanotechnology, vol. 16, no. 10, pp. 2346-2353, 2005.

[19] M. Guzman, J. Dille, and S. Godet, "Synthesis and antibacterial activity of silver nanoparticles against gram-positive and gramnegative bacteria," Nanomedicine, vol. 8, no. 1, pp. 37-45, 2012.

[20] G. Ren, D. Hu, E. W. C. Cheng, M. A. Vargas-Reus, P. Reip, and R. P. Allaker, "Characterisation of copper oxide nanoparticles for antimicrobial applications," The International Journal of Antimicrobial Agents, vol. 33, no. 6, pp. 587-590, 2009.

[21] A. Azam, A. S. Ahmed, M. Oves, M. S. Khan, S. S. Habib, and A. Memic, "Antimicrobial activity of metal oxide nanoparticles against Gram-positive and Gram-negative bacteria: a comparative study," The International Journal of Nanomedicine, vol. 7, pp. 6003-6009, 2012. 

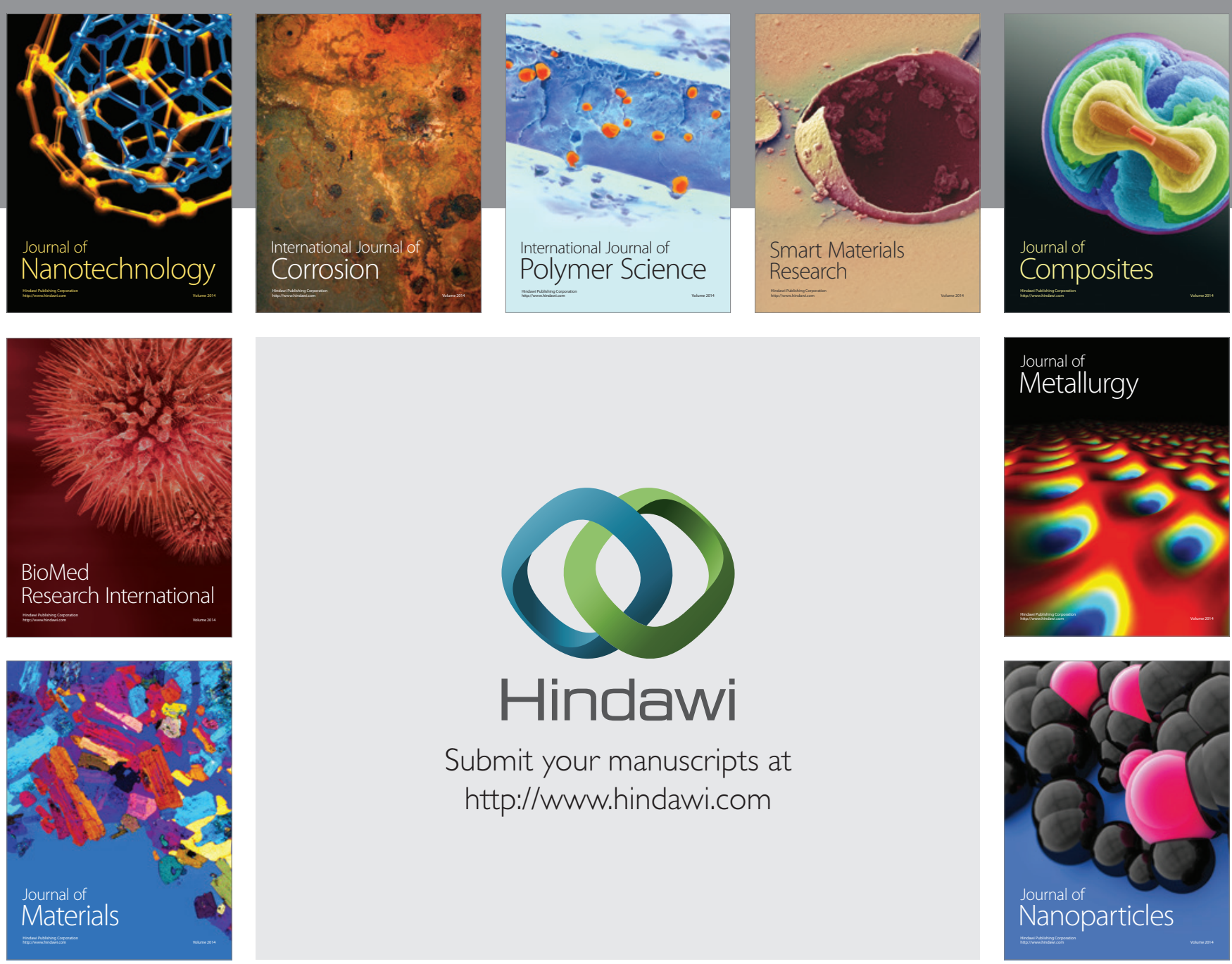

Submit your manuscripts at http://www.hindawi.com
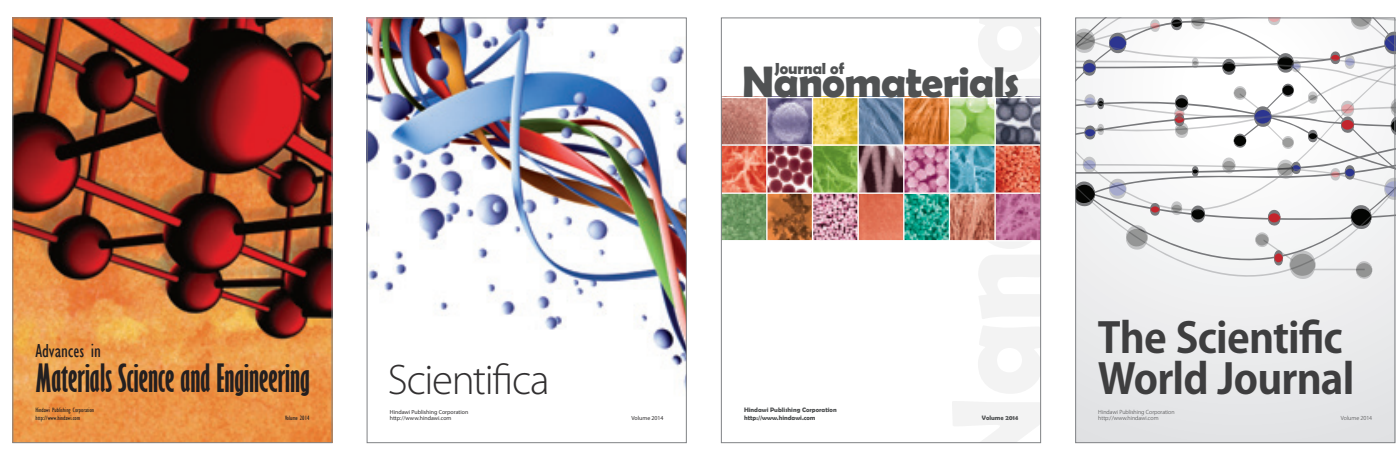

\section{The Scientific World Journal}
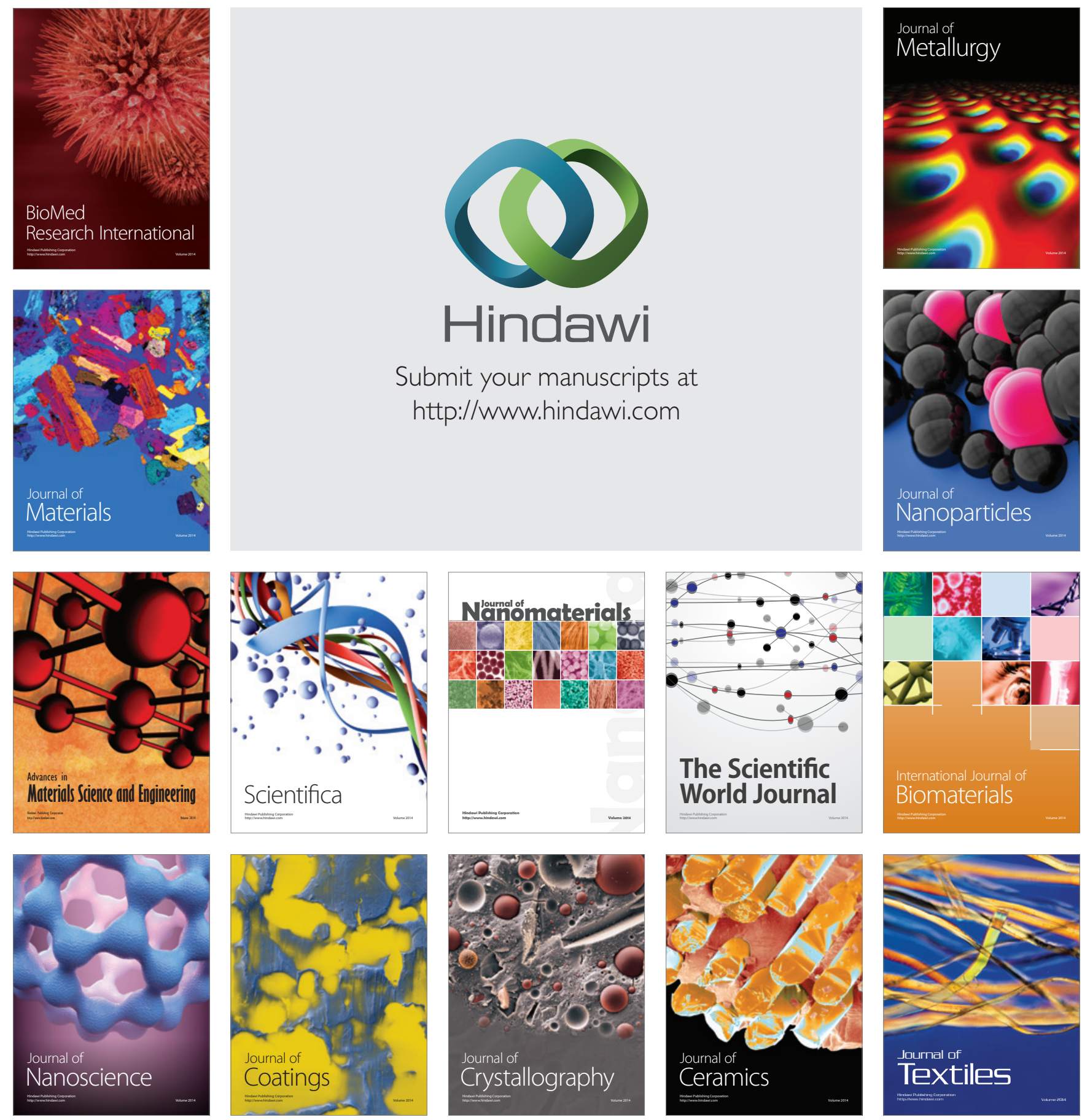